\title{
A STUDY OF SURGICALLY REMOVED SPECIMENS OF BREAST, WITH SPECIAL REFERENCE TO SCLEROSING ADENOSIS
}

\author{
BY \\ A. T. SANDISON \\ From the Departments of Pathology, the University and Western Infirmary, Glasgow
}

(RECEIVED FOR PUBLICATION JULY 13, 1957)

It is now generally accepted that carcinoma of the breast is not restricted to the middle-aged or elderly woman and that a mass in the breast in a woman of any age must be regarded as malignant until it is proved to be benign. This recognition, which has recently been re-emphasized elsewhere (Sandison, 1955), has led to a considerable increase in the demand by surgeons for immediate examination of frozen sections in the theatre in cases of a mass in the breast of younger women. In many instances such examinations will quickly show whether or not a lesion is malignant. The appearance known as sclerosing or fibrosing adenosis may present, especially to the less experienced pathologist, a puzzling picture, and one which may erroneously be diagnosed as carcinoma. In sections prepared by the paraffin embedding method the appearance is less likely to be misinterpreted as carcinoma, but even here difficulty in interpretation has been known. This difficulty is especially important, since sclerosing adenosis is most characteristically seen in younger women in whom mastectomy leads to greater mental distress than in older women. It therefore seems worth while to indicate the frequency with which this picture of sclerosing adenosis has been encountered in the examination of surgically removed breasts or portions of breasts in a fiveyear period in this laboratory during which just over 1,000 breast specimens were received.

The salient features of sclerosing adenosis may be outlined as follows. It produces a firm, mobile nodular or discoid lump in the breast, most frequently in younger women, and is thought to be due possibly to some temporary hormonal imbalance (Dawson, 1954). The naked-eye appearance is that of a greyish-white nodular mass with hyperplastic lobular areas sometimes associated with cysts. Histological examination confirms the lobular nature of the lesion-a most important diagnostic point. The cytological character varies with the phase at which the condition is seen. There is an early florid phase (Fig. 1) which regresses and goes on to an actively sclerosing stage and a final fibrosed lesion (Fig. 2). In the florid phase epithelial and myoepithelial hyperplasia in the lobules dominates the picture with the formation of narrow tubules or solid cords of cells. The stroma is delicate, the cells active, and mitotic figures may be present (Figs. 3-5). Later, as the lesion regresses, there is proliferation of connective tissue stroma till finally the epithelial cords are attenuated and compressed by fairly dense hyaline connective tissue. This appearance is one readily mistaken for scirrhous spheroidal cell carcinoma of the breast, especially if viewed only under the high power of the microscope. It cannot be too strongly emphasized that in the study of breast tissue, especially in frozen sections, very great weight must be given to the impression obtained under very low magnification with a scanning objective (e.g., $\times 4$ ) and preferably a wide-angle eye-piece, which gives a well-illuminated large field.

\section{Method}

In all instances the original reports of the naked-eye and microscopic findings were consulted and the sections were re-examined, but the cases were allocated to groups according to the diagnosis made on re-examination of the sections. These groups consisted of :

(a) True neoplasm, i.e., carcinoma, fibroadenoma, and papilloma.

(b) The mastopathies subdivided into hyperplastic cystic disease, characterized by intraductal or intra-acinar hyperplasia (epitheliosis), and simple fibrocystic disease in which there was no epithelial hyperplasia but which might show some degree of lobular hyperplasia (adenosis), and to this group sclerosing adenosis is probably related. 


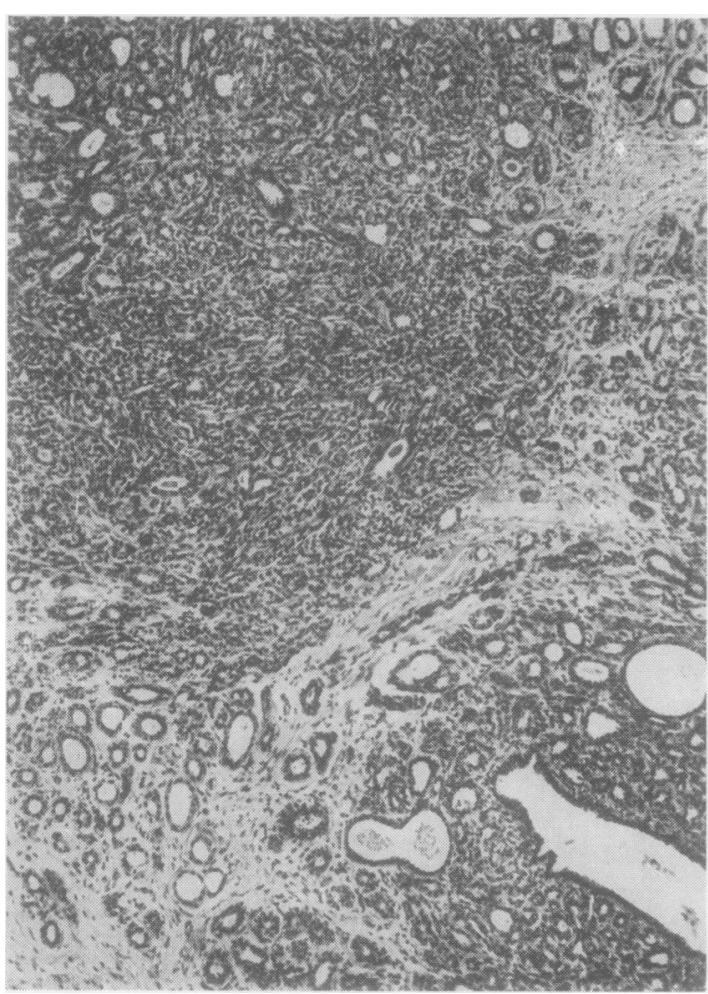

FIG. 1.-Low-power view of sclerosing adenosis (florid phase) in a portion of the right breast of a 27 -year-old woman who complained of a lump in the breast for three weeks. Haemalum and eosin, $\times 65$.

(c) The infective mastitides, lipophagic reaction, lactation effects, and a small miscellaneous group.

Sclerosing adenosis was also regarded as a primary group where it appeared probable that it was the condition for which surgery had been undertaken. A further note was made also of all cases in which sclerosing adenosis was an incidental finding. In this way the minimal incidence has been established. The occurrence of sclerosing adenosis as a secondary feature in breast pathology is much higher than as a primary condition presenting as a palpable mass. It is therefore possible that frozen sections of breast in other conditions may show foci of sclerosing adenosis, the recognition of which is important to avoid mistakes in diagnosis.

\section{Material}

The survey comprised a review of the sections of all breast or portions of breast received in this department over a four-year period from 1950 to 1954. The total number of specimens examined was 1,029 , of which 1,010 were female.

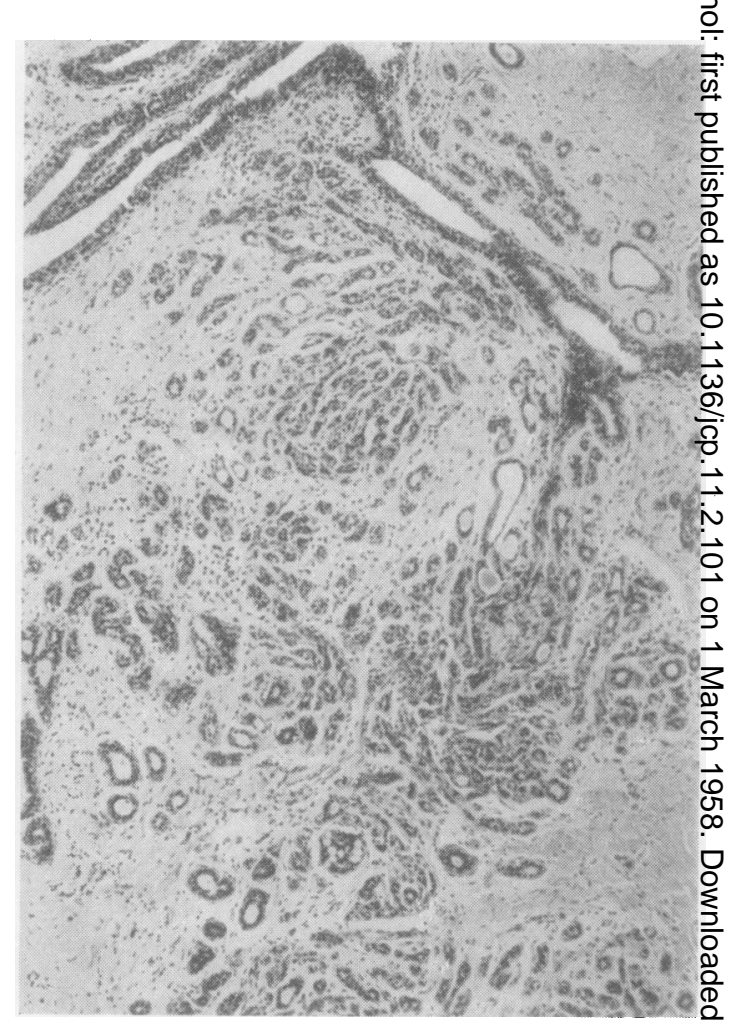

FIG. 2.-Low-power view of sclerosing adenosis (sclerosed phase) in $\overline{\bar{O}}$ portion of right breast of a 40-year-old woman who complained 3 of a lump in the breast after pregnancy two years previously. Haemalum and eosin, $\times 65$.

The major findings in the male breasts are classified in Table $\mathrm{I}$, and those in the female? breasts in Table II. Sclerosing adenosis does not 3 occur in the male because of the absence of lobular formation.

Included in the miscellaneous group were two lipomata, one large simple adenoma, one epithelial 음 tumour of low-grade malignancy, one angio-endo- $\frac{D}{2}$ thelioma, one secondary melanoma, two cases of tuberculosis, eight mammary duct ectasias, and N one simple mammary hypertrophy.

The age distribution of the lesions is shown in Table III, from which some facts of interest $\omega$ emerge. It will be seen that fewer specimens were received from women in the second decade of life than in any other until the ninth decade. Under $\stackrel{\Phi}{\Phi}$ the age of 20 fibro-adenoma was the common ? lesion while the only other seen was intraduct $\frac{7}{0}$ papilloma. Two of the fibro-adenomata were of $\frac{\vec{\Phi}}{\mathbb{D}}$ foetal type. In the third decade occasional cases $\stackrel{\odot}{\mathbb{D}}$ of carcinoma appeared, although fibro-adenoma $\stackrel{\odot}{\square}$ was much the commonest lesion, with occasionalo cases of infective mastitis and lactation effect. In 0 


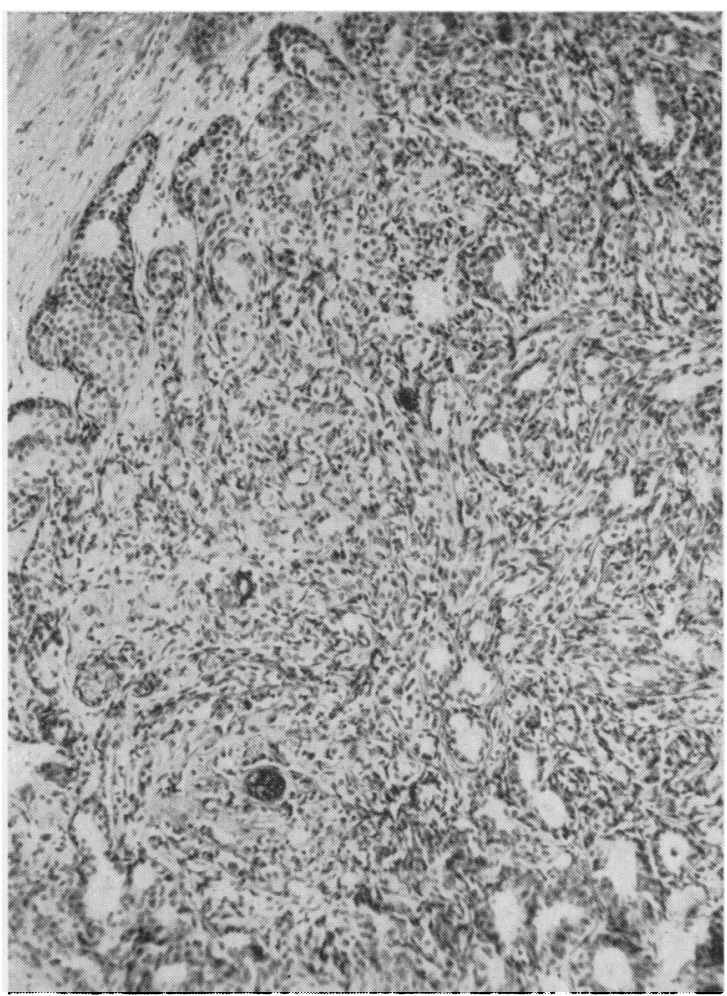

FIG. 3.-Sclerosing adenosis in the florid phase in the left breast of a 48-year-old woman who complained of a lump in the breast for one year. Haemalum and eosin, $\times 90$.

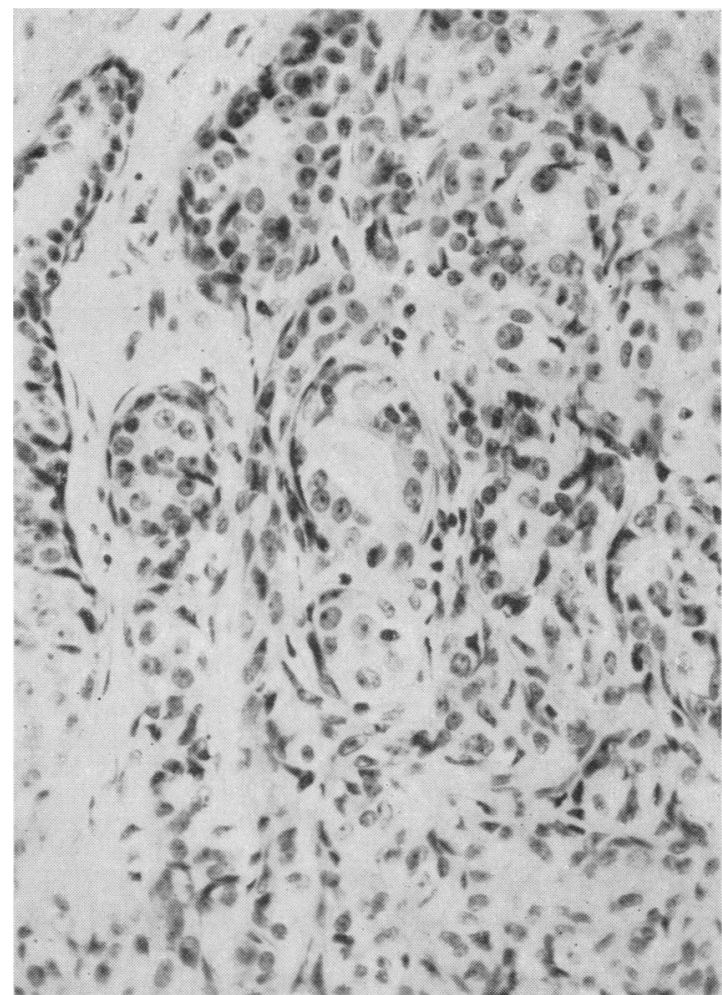

FIG. 4.-Higher power view of florid phase sclerosing adenosis in the same case as Fig. 3 to show great cellularity. Haemalum and eosin, $\times 250$.

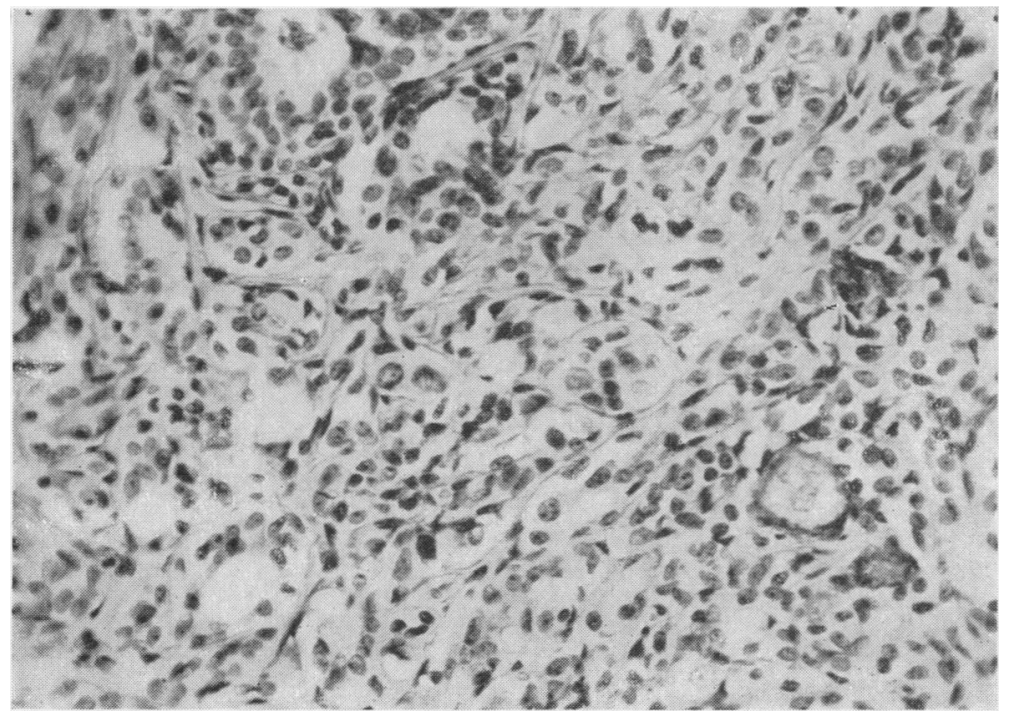

Fig. 5.-Another field from the same case. The myoid element is well shown. Haemalum and eosin, $\times 250$. 
TABLE I

FINDINGS IN MALE BREASTS

\begin{tabular}{|c|c|c|c|}
\hline \multicolumn{3}{|l|}{ Diagnosis } & $\begin{array}{l}\text { Number } \\
\text { of Cases }\end{array}$ \\
\hline $\begin{array}{l}\text { Carcinoma } \\
\text { Physiological hypertrophy or gynaecomastia } \\
\text { Infective mastitis } \ldots \\
.\end{array}$ & $\begin{array}{l}\cdots \\
\cdots\end{array}$ & $\begin{array}{l}\cdots \\
\cdots \\
\cdots\end{array}$ & $\begin{array}{r}3 \\
15 \\
1\end{array}$ \\
\hline & Total & $\ldots$ & 19 \\
\hline
\end{tabular}

TABLE II

FINDINGS IN FEMALE BREASTS

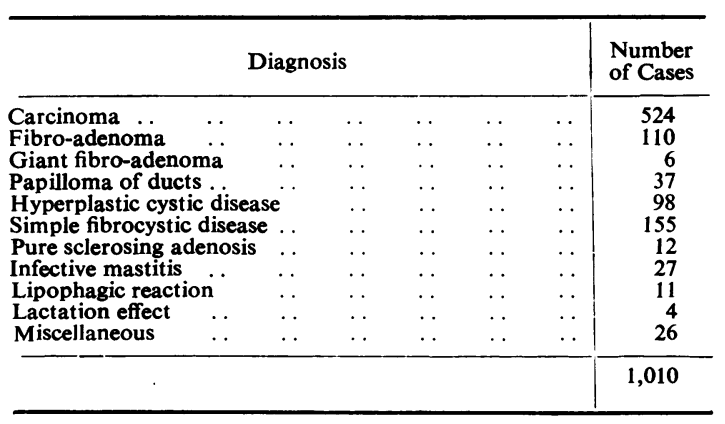

the fourth decade carcinoma was as frequent as fibro-adenoma. Infection and lactation effects were still seen, but now hyperplastic cystic disease (epitheliosis) was fairly common. In the fifth decade the maximum incidence of breast specimens was attained. Carcinoma was by far the most frequent lesion with hyperplastic cystic disease and fibrocystic disease each much less common. Fibro-adenoma was now relatively infrequent, but papillomata were at their maximum incidence. Occasional cases of infection still occurred. In the sixth decade the frequency of carcinoma was unchanged, but hyperplastic cystic disease, simple fibrocystic disease, and fibroadenoma were relatively rare. Infective mastitis still occurred in the seventh decade ; the frequency of carcinoma was again relatively unchanged, but all other conditions were relatively rare. In the eighth decade the number of cases of carcinoma was only half of that seen in each of the previous three decades, while over the age of 80 carcinoma, although uncommon, was the sole lesion for which surgery was attempted.

Of 524 carcinomas, 40 occurred in women under the age of 40 , while in the next three decades the incidence remained remarkably stable at about 130, falling off to about half that number in the eighth decade. Simple fibrocystic disease, hyperplastic cystic disease, and duct papillomata lead most frequently to operation in the fifth decade. It may be that these are in fact most common at about the time of the menopause or that in this period of life surgery is more frequently advised.

Fibro-adenoma occurred from the second to the eighth decade but is commonest in the third and fourth. Giant fibro-adenoma was only about oneeighteenth as common and occurred most frequently in the seventh decade. Duct papillomata were twice noted in young girls, but were seen most often in the fifth decade. Infective mastitis was largely a disease of the third and fourth decades, i.e., the reproductive period, while fat necrosis occurred in the same group and also rarely affected older women.

Of the male breasts examined all three carcinomas were seen after the age of 50 , but of the cases of gynaecomastia or hyperplasia almost as

TABLE III

AGE DiSTRIBUTION OF MALE AND FEMALE CASES

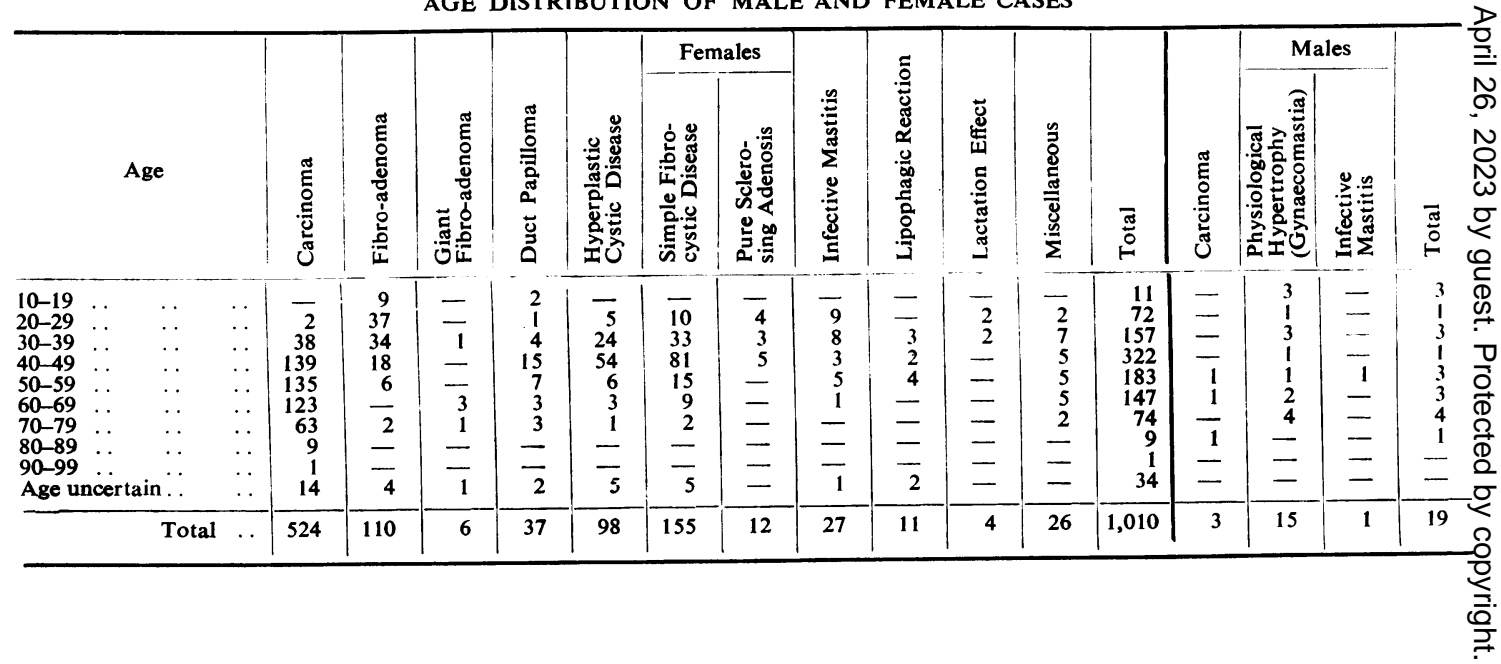


many were seen before this age as after it. These included three instances in boys in the second decade, which are best regarded as adolescent hyperplasias.

\section{Sclerosing Adenosis}

Sclerosing adenosis was present in breast specimens from 12 women as a relatively pure primary lesion. The age distribution may be seen in Table III. In three of those women in whom mastectomy had been done because of an associated papillomatosis with nipple discharge, sclerosing adenosis was present both in the original biopsy and in the breast when removed. In the remaining nine women biopsies were done in four instances and primary local mastectomies in the remaining five.

Of these women, 10 were married and only two single, and the history of a lump varied from three weeks to 13 years. In one unmarried woman aged 44 the lump had been present for 13 years and was said to have followed a non-puerperal abscess. In another, a married woman aged 39 years, the lump was thought to have followed a puerperal abscess eight years before. In the majority of cases there was no history of gross menstrual upset. One 24-year-old woman had, however, noted a mass during the fifth month of her only pregnancy two years previously; the child was not breast-fed, and for seven months before operation there had been severe menorrhagia. Another woman, aged 44, also complained of menorrhagia for three months before operation. In one instance a woman aged 29 had had, three weeks before mammary biopsy, an abdominal operation at which the pelvic organs were seen to be entirely normal.

In the majority of instances the clinical impression was one of mobile, firm nodularity of breast substance although occasionally a discoid mass was felt. In only one woman, aged 48 , had the nipple discharged; the discharge was purulent in appearance and when examined cytologically (Sandison and Walker, in preparation) contained histiocytes or " colostrum corpuscles," some red blood cells, and epithelial cells. This appearance is characteristic of papillomatosis and was due, not to the sclerosing adenosis, but to a concurrent multiradiculate papillomatosis. It may be of importance to note that this woman had had, shortly before mastectomy, a course of oestrin for menopausal symptoms.

Microscopically all of the cases showed a lobular hyperplasia with myoepithelial and epithelial participation. In six cases, of which two occurred in the second decade, one in the third, and three in

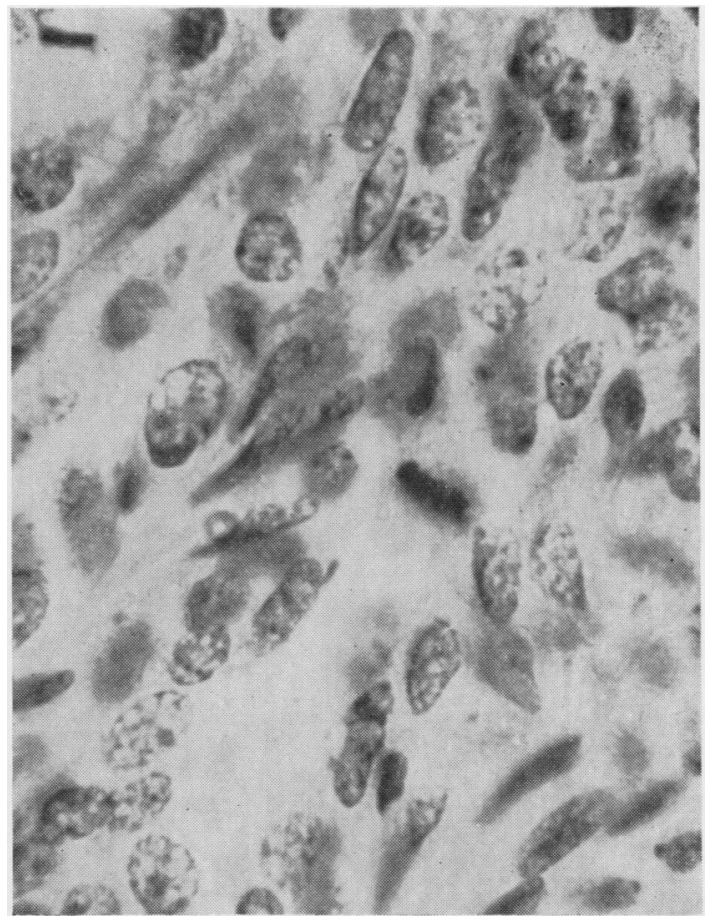

FIG. 6.-Mitosis in florid sclerosing adenosis in a biopsy from the right breast of a 31-year-old woman who had complained of a lump for five years, becoming larger more recently. Haemalum and eosin, $\times 1,000$.

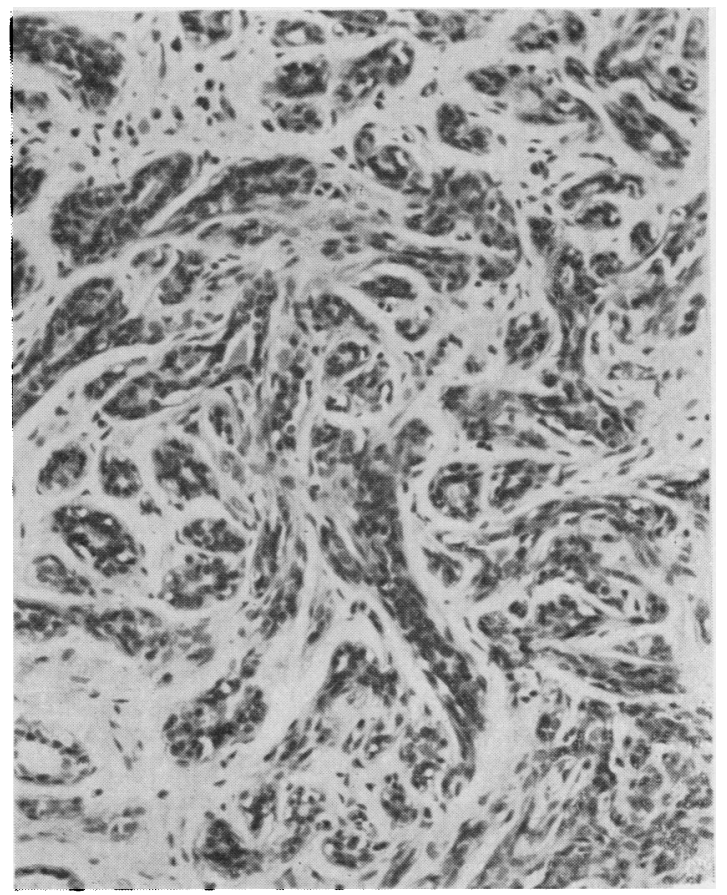

FIG. 7.-High-power view of sclerosing adenosis in sclerosed phase showing cords of involuting ce!ls which may be mistaken for scirrhous carcinoma. Haemalum and eosin, $\times 160$. 


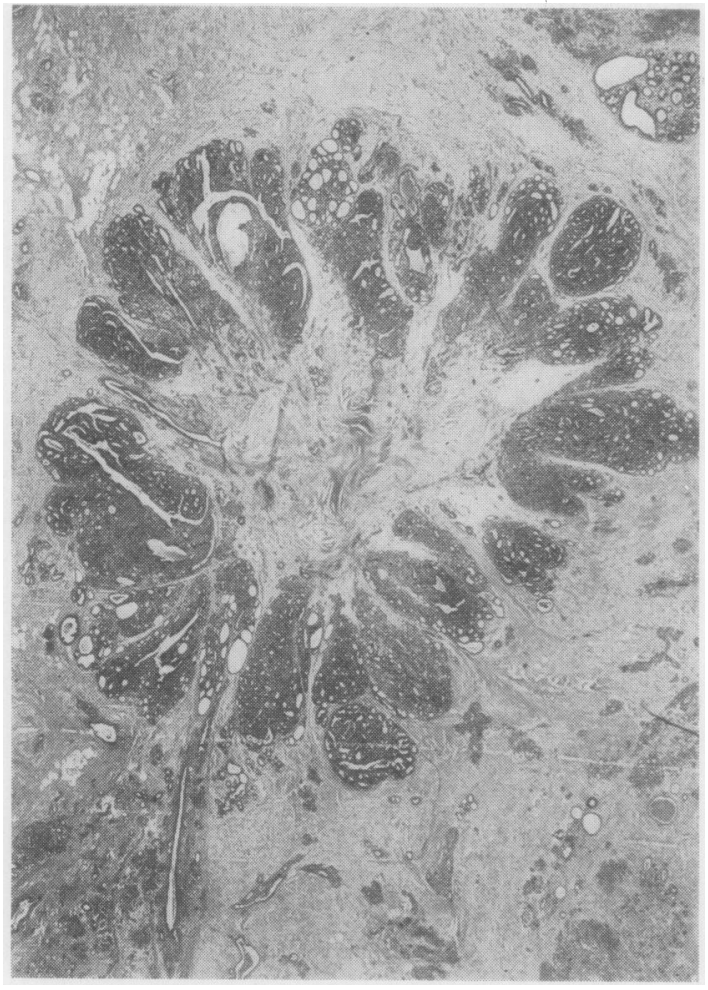

Fig. 8.-Rosette of lobules around a terminal duct; all of these show sclerosing adenosis. Haemalum and eosin, $\times 10$.

the fourth, the appearances were largely of the florid type. In the instance occurring in the third decade mitotic activity was especially marked (Fig. 6). In the remaining cases the florid phase was less obvious, more or less fibrosis had occurred, and the appearances tended to mimic those of scirrhous infiltrative carcinoma (Figs. 2, 7). In 10 cases there was some degree of microcystic formation and in seven there were also cysts lined by metaplastic "pink" epithelium of socalled apocrine type. In only two instances was there associated epitheliosis of ducts, but in nine there were minute papillomata in ducts. This association appears to be significant.

In three cases where both biopsy and later mastectomy specimens were available the condition was seen to be present in both. In cases where primary mastectomy was carried out, the condition, although most obvious in the focal lesion for which the operation was done, was also present to a similar or lesser extent in other regions of the breast.

In one woman, who was aged 44 and unmarried, there was a peculiar rosetted arrangement around a central fibrous core (Fig. 8). This is considered to be a change in several lobules arranged at the $\stackrel{5}{?}$ termination of a single duct.

Sclerosing adenosis as a complicating lesion was present as a secondary lesion in 73 breasts ; 28 of $\frac{\bar{\sigma}}{\vec{D}}$ these were carcinomatous, six contained large $\stackrel{\square}{\circledR}$ papillomata, and two fibro-adenoma, 23 were associated with only simple fibrocystic disease, $13 \vec{A}$ with hyperplastic cystic disease, and one with in- $?$ fective mastitis. The age distribution of these $\vec{\omega}$ cases is shown in Table IV with that of primary sclerosing adenosis.

TABLE IV

SCLEROSING ADENOSIS AS COMPLICATING LESION

\begin{tabular}{|c|c|c|c|c|c|c|c|c|}
\hline Age & 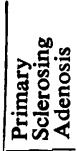 & 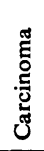 & 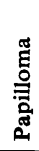 & 总 & 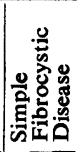 & 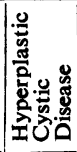 & 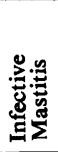 & 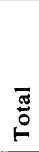 \\
\hline $\begin{array}{ll}20-29 & \ldots \\
30-39 & \ldots \\
40-49 & \ldots \\
50-59 & \ldots \\
60-69 & \ldots \\
70-79 & \ldots\end{array}$ & $\begin{array}{r}4 \\
3 \\
5 \\
- \\
-\end{array}$ & $\begin{array}{r}-1 \\
10 \\
10 \\
3 \\
4\end{array}$ & $\begin{array}{l}1 \\
1 \\
4 \\
- \\
-\end{array}$ & $\begin{array}{l}\bar{z} \\
\frac{2}{z} \\
-\end{array}$ & $\begin{array}{r}1 \\
5 \\
11 \\
3 \\
2 \\
1\end{array}$ & $\begin{array}{l}-5 \\
5 \\
2 \\
1 \\
-\end{array}$ & $\begin{array}{l}1 \\
= \\
=\end{array}$ & $\begin{array}{r}7 \\
15 \\
37 \\
15 \\
6 \\
5\end{array}$ \\
\hline Total & 12 & 28 & 6 & 2 & 23 & 13 & 1 & 85 \\
\hline
\end{tabular}

Of these 28 women with carcinoma, six were single and 22 were married. One woman, aged $49, \stackrel{\mathbb{Q}}{\varrho}$ had undergone a course of oestrin therapy for $\overrightarrow{0}$ menopausal symptoms shortly before mastectomy. 3 Another, aged 50, had a further mastectomy about 18 months later and the second breast also showed? well-marked sclerosing adenosis as the primary condition. In this case the condition was there-? fore bilateral. Yet another woman, aged 64, died 3 several days after mastectomy, and it was possible to examine the remaining breast at necropsy. This $\frac{3}{3}$ showed epitheliosis, papillomatosis, cyst formation, and sclerosing adenosis in both the florid and fibrosing stages. In the breast removed for car $\frac{D}{0}$ cinoma the condition was largely in the more florid stage. The ovaries at necropsy showed a fairly cellular stroma according to the criteria of Sommers and Teloh (1952) and the endometrium was rather hyperplastic. This case is of especial ${ }^{\omega}$ interest because the appearance of the endo-? metrium suggested some degree of continuing oestrogen activity. In two instances it was of interest to note areas of incomplete involution of lactation effect, in view of the belief that perver- $\frac{0}{0}$ sion of lactation may play a part in the aetiology of the lesion.

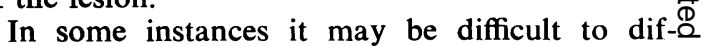
ferentiate between sclerosing adenosis and scirrhous carcinoma when both are present in then 
same section. The lobular distribution of the changes in sclerosing adenosis provided a useful basis for differentiation, and detailed comparative cytological examination may reveal considerable differences. It is, in fact, a salutary exercise to attempt this differentiation in cases where the two types of lesion are closely intermingled. In one instance, in a woman aged 48, a carcinoma of largely intraductal and intra-acinar type was complicated by the presence of sclerosing adenosis of rather florid degree and in which the component elements were difficult to distinguish. This is not surprising, since both intra-acinar carcinoma and the proliferative phase of adenosis are essentially lobular, highly cellular, and both may show active growth with mitotic figures. It is also interesting that in this case a part of the area of active adenosis showed some degree of apocrine metaplasia.

Six women showed sclerosing adenosis as a secondary lesion to papillomatosis of the breast. This association of papillomatosis and sclerosing adenosis is of considerable interest since it will be recalled that in nine women who were considered to show sclerosing adenosis as the primary breast condition there were also associated microscopic papillomatosis. In a total of 85 women who showed either primary or incidental sclerosing adenosis in some degree, some 15 also showed papillomatosis in some degree, i.e., just over $17 \%$. On the other hand, of 37 women who showed papillomatosis as a primary condition only, six showed sclerosing adenosis, a proportion of $16 \%$. Of these six women showing an association of sclerosing adenosis with primary papillomatosis, only one was unmarried. One of the women, aged 25 , complained of menstrual irregularity. Of two women who showed sclerosing adenosis in association with fibro-adenoma, both were married, in the fifth decade of life, and no history of menstrual irregularity was obtained. One fibro-adenoma was intracanalicular and the other of mixed type.

Simple fibrocystic disease of the breast was the commonest primary condition to be associated with sclerosing adenosis. Twenty-four cases in all were noted. Of these, five women were known to be unmarried. In none of these cases was epitheliosis or intraduct hyperplasia a feature. In the majority there was some degree of apocrine metaplasia in the cysts and also frequently a varying degree of simple adenosis of physiological type. One breast from a 35-year-old woman showed evidence of incomplete involution of lactation.

Sclerosing adenosis complicated hyperplastic cystic disease, in which there was some degree of epitheliosis or intraduct hyperplasia, in 13 cases
$(13 \%)$. Of these women three were unmarried. In only one instance was there a definite history of menorrhagia. Three of the cases showed quite marked epitheliosis ; in the remainder the hyperplasia was of only moderate degree.

The one instance of sclerosing adenosis as a secondary feature in chronic infection occurred in a 27-year-old married woman who showed a nonspecific chronic infection of six years' duration. In this instance only one small focus of sclerosed adenosis was seen.

When all cases showing sclerosing adenosis in some degree are considered together the incidence was 28 instances in 524 cancerous breasts (5.3\%) and 57 instances in 486 non-cancerous breasts $(12.2 \%)$.

\section{Discussion}

Sclerosing adenosis although recognized was not named by the older authorities, e.g., Muir (1941) or Cheatle and Cutler (1931). A brief description of this condition is given by Ewing (1940), who points out that more than any other condition in the breast it is likely to be mistaken for carcinoma. Since then this warning has been reiterated by Boyd (1947), while Foot (1945) mentions "diffuse fibrosing adenomatosis" but contents himself with stating that its presence does not alter the prognosis of fibrocystic disease. Saner (1950) regards the condition as a form of hyperplastic cystic disease which may give rise to difficulty in diagnosis on immediate examination in the theatre.

Mulligan (1951) gives a useful summary of his views on sclerosing adenosis. It is much more commonly seen as an incidental microscopic finding than as a presenting discrete mass which is in any case rarely large. The lesion is most commonly found between the ages of 20 and 40 years ; it begins within the lobules or terminal ductules and in the early stage there is considerable proliferative activity. Throughout the evolution of the lesion a distinct lobular pattern persists. In the later phase connective tissue tends to compress irregularly the attenuated cords of epithelial cells and a bizarre pattern may thus be produced distinctly reminiscent of scirrhous carcinoma.

Willis (1953) also emphasizes this collapse, atrophy, and distortion of the epithelial elements with stromal fibrosis, and states that there is a superficial resemblance to infiltrating scirrhous carcinoma. He states that mistaken diagnoses may be made, especially in frozen sections, and that the only safeguard is experience in the recognition of fibrosing adenosis at the different evolutionary stages and insistence on paraffin sections to confirm all frozen section diagnoses. 
Ackerman (1953) has also summarized his views in an addendum to his remarks on chronic cystic mastopathy. He considers sclerosing adenosis to be a highly proliferative form of simple cystic disease of rather uncommon type, and gives the incidence as $1 \%$ of benign breast lesions.

Stewart (1950) gives a detailed consideration of fibrosing adenosis in the section on lesions simulating carcinoma in his atlas of breast tumours. Stewart points out that the fibrosing phase is that most commonly recognized, but that it is also important to recognize the florid phase of epithelial proliferation. The age incidence given is similar to the experience of Mulligan (1951). Stewart also emphasizes that this lesion is especially liable to be over-diagnosed by pathologists who only encounter small numbers of breast specimens. He describes instances where not only mastectomy but post-operative radiotherapy and castration had been recommended, and deprecates the unnecessary "single-breasted" state of not a few young women in the third decade of life because of this diagnostic failure.

He gives detailed accounts of the morbid anatomy and histology of the lesion, which is discrete, often coarsely nodular, less firm than carcinoma, and usually distinctly lobulated. Stewart concedes that sclerosing adenosis may occur also in microscopic foci and that the only real difference between this form and that detected as a palpable mass is that the former occurs in miniature.

Ingleby and Gershon-Cohen (1954) have recently reviewed the problem of adenosis generally. They state that in the normal breast in the post-menstrual phase ductules bud to form new lobules with deeply staining cells. As the cycle progresses both epithelial and basal cells become paler and larger and myo-epithelial cells are formed by formation of blunt processes. Some few days before menstruation begins some secretion appears in the ducts, while the epithelial and basal cells vacuolate. During the period the basal cells break up and the epithelium is shed into the lumen. In the premenstrual phase also the intraductal stroma is loose and oedematous, with scattered mononuclear cells, while after the period this stroma is dense and fibrous.

Ingleby and Gershon-Cohen classify adenosis into four types. Type A consists of lobular hyperplasia with very large lobules or numbers of smaller lobules close together, while in type B, which is the commonest form, the lobules consist of a few more or less dilated ductules with incomplete lobular development. They state that type $\mathrm{C}$ occurs near the tumour in most carcinomas of young women, that epithelial and basal prolifera-

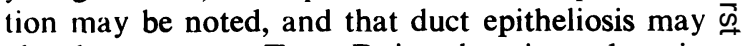
also be present. Type $D$ is sclerosing adenosis, $\frac{0}{6}$ and Ingleby and Gershon-Cohen think this is often formed entirely of myo-epithelial cells and $\frac{\bar{s}}{\partial}$. therefore prefer to entitle this lesion "myoid $\underset{\complement}{\square}$ sclerosis." The validity of this concept of scler- क osing adenosis as well as that of possible pre- $\vec{\circ}$ cancerous potentiality in their type $\mathrm{C}$ adenosis remains uncertain.

Valuable papers on sclerosing adenosis have $\stackrel{\omega}{\mathcal{S}}$ come from Urban and Adair (1949) and Foote and $\overline{ }$ Stewart (1945). The latter authors noted that the lesion was present in some degree in $12.5 \%$ of $\vec{i}$ 200 non-cancerous and $7 \%$ of 300 cancerous breasts studied, and these figures do not differ $\stackrel{\circ}{-}$ greatly from mine, i.e., $12.2 \%$ and $5.3 \%$.

Dawson (1954) has published a comprehensive descriptive article on fibrosing adenosis empha- 3 sizing the fact that it is often unrecognized. She $\frac{0}{3}$ points out not only the possibility of overdiagnosis $\stackrel{5}{\sim}$ and the subjection of the patient to unnecessary $\vec{\theta}$ operative risk, but also of vitiation of statistical ${ }_{0}$ figures for cancer survival rates. She points out that in itself the term " adenosis" carries no pathological implication, and that, especially in older women, involution after pregnancy without lacta-ฏ tion may be slow. Studies of post-mortem breasts $\frac{2}{\mathbb{Q}}$ in this department, to be published later, confirm $\underset{\overrightarrow{0}}{\overrightarrow{7}}$ this observation (Sandison, 1958).

Post-menopausal adenosis may be due to continued hormone secretion by the adrenal cortexô or from other sites. Novak (1952) has speculated on a similar basis for the noted occurrence of post-menopausal endometrial hyperplasia seen in women without functional ovarian tumours. It is of interest to note at this point that Geschicktero (1945) illustrates a case of mastodynia in a patien who received over one million i.u. of oestradiog benzoate over a period of 20 months, and ther photomicrograph shows apparent sclerosing aden osis.

Dawson emphasizes that recognition of the phases of normal growth with possible irregularity or perversion is necessary for an understanding of fibrosing adenosis. She has also found fibrosing adenosis to be commonest in younger marrie $\&$ women and frequently associated with some per version of mammary function. It does, however? occur in younger unmarried subjects and in older patients. Fibrosing adenosis as a localize tumour-like condition she has found to be rare $\frac{\text { P }}{D}$ It is, however, not uncommon as a focal change in the breast as seen in surgically removed specio mens or at necropsy. 
With regard to histological studies, Dawson, who publishes a large number of photographs, agrees that it is essential to recognize the pattern of growth. Dawson's description of the microscopic appearances corresponds closely with those of Mulligan (1951) and Stewart (1950), and with all of these the present study also corresponds closely. Dawson rightly points out that staining by silver methods or by phosphotungstic-acidhaematoxylin shows an intact basement membrane round the distorted glands or cell groups with no evidence of invasion, and that mitoses may occur in epithelial cells in the florid phase and in fibroblasts in the actively sclerosing phase. Dawson suggests that epitheliosis is largely absent in the ducts in sclerosing adenosis, but with this statement the present study is not in full agreement. Epitheliosis may be present although it is often mild. Dawson concedes that epitheliosis may be seen in association with sclerosing adenosis in older women and thinks that the two are not related. It seems possible, however, that disordered hormonal balance may lead to papillary epitheliosis as well as adenosis and the two may not be mutually exclusive. Since it is generally believed that epitheliosis of duct sometimes precedes the development of intraduct neoplasia, the occasional association of sclerosing adenosis and carcinoma is not surprising. Nevertheless it should be emphasized that there is no causal relationship between sclerosing adenosis and mammary neoplasia. It is generally accepted that the sclerosing phase represents an involutionary process which becomes to all intents and purposes quiescent.

There do not appear to be any reports concerning the incidence of sclerosing adenosis in breasts examined at necropsy, but in this department a complete study of the breasts in 800 consecutive female necropsies (Sandison) showed uncomplicated sclerosing adenosis in $3.1 \%$ of all cases, the staging of the lesions being $36 \%$ in the florid,
$36 \%$ in the sclerosing, and $28 \%$ in the sclerosed phase. A further $3.9 \%$ of all cases showed sclerosing adenosis as well as other changes. A detailed report of the findings in this study will be published in due course.

\section{Summary}

The minimal incidence of sclerosing adenosis in surgical specimens of breast, both as a primary condition and complicating other lesions, has been established.

In just over 1,000 female breasts there were 12 primary and 73 secondary instances of the condition. The result of a simple analysis of the total number of specimens examined is also presented.

The significance of sclerosing adenosis is discussed, and the importance of its recognition by the practising surgical pathologist is emphasized.

I am grateful to Messrs. G. Kerr and W. Mason for the photographs illustrating the paper.

\section{REFERENCES}

Ackerman, L. V. (1953). Surgical Pathology. Mosby, St. Louis. Boyd, W. (1947). A Text-book of Pathology, 5th ed. London. Cheatle, G. L., and Cutler, M. (1931). Tumours of the Breast. Arnold, London.

Dawson, E. K. (1954). Edinb. med. J., 61, 391.

Ewing, J. (1940). Neoplastic Diseases, 4 th ed. Saunders, Philadelphia and London.

Foot, N. C. (1945). Pathology in Surgery. Lippincott, Philadelphia.

Foote, F. W., and Stewart, F. W. (1945). Ann. Surg., 121, 6.

Geschickter, C. F. (1945). Diseases of the Breast, 2nd ed. Lippincott, Philadelphia.

Ingleby, H., and Gershon-Cohen, J. (1954). Surg. Gynec. Obstet., 99, 199.

Muir, R. (1941). Text-book of Pathology, 5th ed. London.

Mulligan, R. M. (1951). Syllabus of Human Neoplasms. London.

Novak, E. (1952). Gynecologic and Obstetric Pathology, 3rd ed. Saunders, Philadelphia and London.

Sandison, A. T. (1955). Glasg. med. J., 36, 398

- (1958). A Post-mortem Survey of the Adult Breast in Endocrine Aspects of Breast Cancer. Livingstone, Edinburgh. and Walker, J. C. (1958). The Cytological Examination of and Walker, J. C. (1958). The Cytological Examinat
Nipple Discharge as a Diagnostic Aid. In preparation.

Saner, F.D.(1950). The Breast Structure: Function:Disease. Wright, Bristol.

Sommers, S. C., and Teloh, H. A. (1952). A.M.A. Arch. Path., 53, 160.

Stewart, F. W. (1950). Atlas of Tumour Pathology, Sect. 9. Fasc. 34: Tumours of the Breast. Armed Forces Institute of Pathology, Washington, D.C.

Urban, J. A., and Adair, F. E. (1949). Cancer, $2,625$.

Willis, R. A. (1953). Pathology of Tumours, 2nd ed. Butterworth, London. 